\title{
Connotation Analysis and Public Cognition of Social Justice and the Appeal of Vulnerable Groups
}

\author{
Yadi Wang \\ Teaching Department of Political Theory, Nanyang Institute of Technology, Nanyang, Henan, China
}

Keywords: Social Justice; Connotation Analysis; Cognitive Psychology; Vulnerable Groups; Psychological Appeal.

\begin{abstract}
Nowadays, the attention and realization of social justice has become one of the important issues in building a harmonious socialist society. But in reality, the realization of a "fair society" takes a long way to go. "Vulnerable groups" has a large proportion of the members of the society. It not only impedes social justice, but also affects social stability and development. This paper first analyzes the connotation of social justice from several different perspectives. Then it discusses the public cognition of the status quo and future trends of social justice through the network survey. Finally, from the perspective of vulnerable groups, this paper expounds the psychological appeal of this key group to social justice.
\end{abstract}

\section{Introduction}

Nowadays, the attention and realization of social justice has become one of the important issues in building a harmonious socialist society. In fact, "justice" is the desire of social subjects. In certain types of society, justice is partial. It belongs to some interest groups[1]. But in the socialist society, people are the masters of the state. They are the "main body of the society". Therefore, seeking justice in such a society is to realize the "universal justice " of all citizens. Let "the masters of the state" be able to fully enjoy the achievements of national development and participate in all fields of economic and social development in an equal manner.[2] But in reality, the realization of a "fair society" takes a long way to go. This paper starts from the vulnerable groups which have the strongest psychological appeal to "fair society" and begins to analyze from the connotation of social justice theory.

\section{The Connotation of Social Justice Theory in Modem Society}

Rights are Equal. In the area of social justice, "rights are equal" is the most basic requirement. Equality of rights is the most basic "respect" for members of society. But the equality of any right can only be achieved under "open" conditions. In other words, it is not enough to achieve equality based on social wealth. What is needed is that everyone should have the same legal right to have the same possibility in the course of achieving a certain goal. In Rawls's opinion, Anyone should have the broadest and basic rights and the right to freedom as everyone else. In order to achieve this, there is a need for equal distribution of basic rights and obligations. Of course, the burden of social cooperation should also be distributed equally to the maximum degree.[3]

Opportunities are Equal. From the perspective of human sociology, in the course of the development of human society, the acquisition of any right or any right of justice requires an equal opportunity as a carrier. In Rawls's opinion, social and economic inequality refers to that when being consistent with the storage principle of justice, only the unequal distribution that gives compensation to the least advantages can be satisfied. Any individual or group can have a better life than others only if they have a way of benefiting the least advantaged to make a profit.[4-5] From this point of view, we find that equality of opportunity first manifests itself as "starting equal". That is, the starting point of competition in social life and other areas should be equalization and rationality. Of course, in the process of development, different individuals may have different gifts, talents and opportunities, 
coupled with differences in the degree of education and the extent of their own efforts. All of these will produce a large degree of individual differences. Therefore, the equality of opportunity based on "starting equality" is not "the same" for all members of society. It is for those individuals who are roughly equal in the level of intelligence or labor force, to enjoy the same basic opportunities basically.

Results are equivalent. The "results are equivalent" that we advocate refers to the fact that the social activities of the public need to be achieved through different proportions. That is, the results should not be fully expressed as "equal", but "equivalent".[6] Of course, this kind of social behavior in the form of "result equivalence" is likely to produce "social exclusion". Those groups or individuals who can't provide products or services to the society or individuals are likely to be excluded.[7] Therefore, "result equivalence" should be based on "human rights" in order to protect basic rights and basic dignity of these individuals and groups. From this perspective, there is a clear answer to the results of social justice. That is, the equivalence of the results requires the public tend to be reasonable and necessary in the aspect of obtaining wealth and income, even if there is a gap, it should be reasonable and necessary.

\section{Public's Cognition of Social Justice - Based on the Analysis of Network Survey}

From June to August in 2012, this paper explored the issue of "social justice" through six network media: Xilu Forum, Sina Forum, Tianya Community, Sohu Community, Tom Community, MOP Community. The questions are: "What do you think is the current level of social justice?"; "What do You think is the most important justice in the Society?"; "What do you think is the primary task for building social justice?"; "What do you think of the development trend of our society justice?". There were 8797 valid responses. The investigation process met the research requirements tested by the relevant experts. After compiling data, gathering statistics and analyzing the survey results, the following conclusions are made.

The Statistic Analysis of the Question "What Do You Think is the Current Level of Social Justice". On this issue, the respondents' conclusions are not satisfactory (Table 1). Only 6.0\% of the respondents thought the society was "very fair". And $22.5 \%$ of the respondents thought it was "comparatively fair". $43.2 \%$ of them thought it a "not so fair" society. $28.3 \%$ of the respondents thought the current society was "unfair". This shows that the public's assessment of the current social justice is low. From different survey "regions", it is easy to find that different online media have no significant differences in the cognition of current social justice (Figure 1). This shows that there is a high degree of public consistency in judging social justice.

Table 1 the statistic analysis of the responses toward question 1 (\%)

\begin{tabular}{ccccc}
\hline media & very fair & comparatively fair & not so fair & unfair \\
\hline Xilu & 6.5 & 23.6 & 45.3 & 24.6 \\
Sina & 4.3 & 22.9 & 39.6 & 33.2 \\
Tianya & 6.4 & 19.5 & 47.5 & 26.6 \\
Sohu & 7.5 & 20.7 & 40.2 & 31.6 \\
Tom & 3.5 & 20.6 & 47.5 & 28.4 \\
MOP & 7.7 & 27.6 & 39.3 & 25.4 \\
average & 6.0 & 22.5 & 43.2 & 28.3 \\
\hline
\end{tabular}




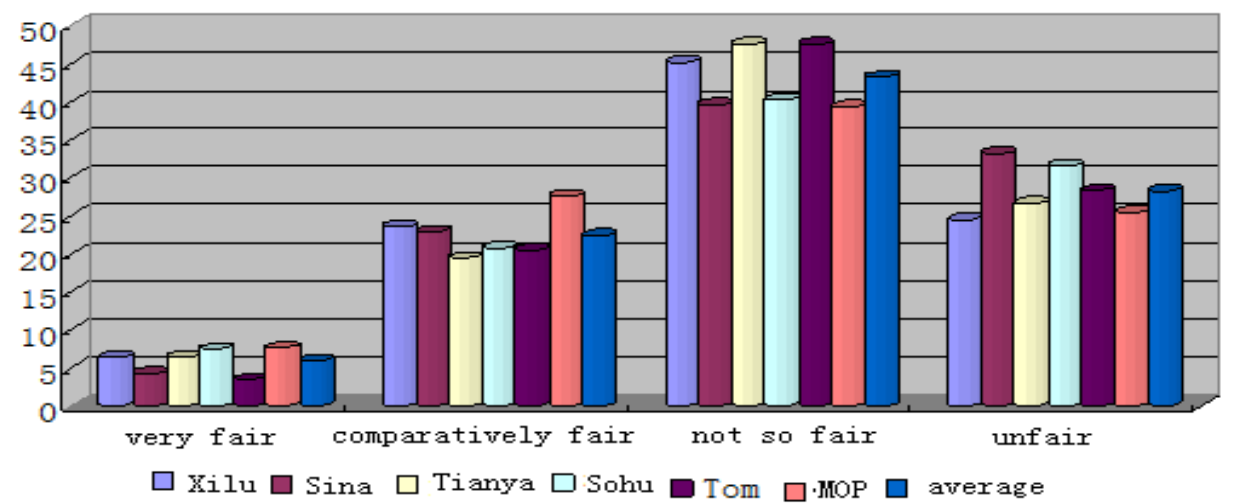

Figure 1 the cylindrical plot of the statistic analysis of the responses toward question 1

The Statistic Analysis of the Question "What Do You Think is the Most Important Justice in the Society?" The survey(Table 1) shows that education justice, employment justice, income justice and justice of social insurance are the focus of public attention. The proportion is $23.0 \%, 13.3 \%$, 26.1\%, and 33.0\% respectively. "Other options" accounts for $4.7 \%$. This shows that social insurance has become the focus of public concern. The options of income justice and education justice also account for large proportion. It is found in the further research (Figure 2) that there are some differences in the results of different survey "regions".

Table 2 the statistic analysis of the responses toward question 2 (\%)

\begin{tabular}{cccccc}
\hline media & education & employment & income & $\begin{array}{c}\text { social } \\
\text { insurance }\end{array}$ & other \\
\hline Xilu & 27.4 & 11.8 & 25.3 & 33.2 & 2.3 \\
Sina & 22.6 & 10.4 & 28.6 & 34.1 & 4.3 \\
Tianya & 19.7 & 15.5 & 20.6 & 38.9 & 5.3 \\
Sohu & 30.5 & 9.6 & 30.6 & 25.7 & 3.6 \\
Tom & 19.3 & 12.2 & 25.9 & 36.5 & 6.1 \\
MOP & 18.3 & 20.5 & 25.3 & 29.5 & 6.4 \\
average & 23.0 & 13.3 & 26.1 & 33.0 & 4.7 \\
\hline
\end{tabular}

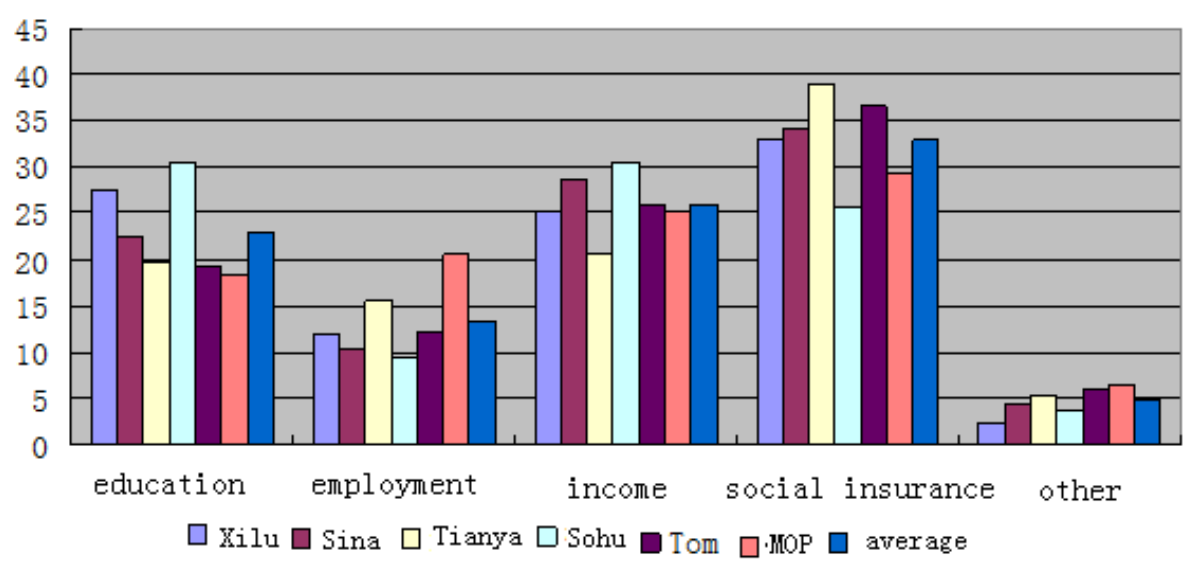

Figure 2 the cylindrical plot of the statistic analysis of the responses toward question 2

The Statistic Analysis of the Question "What Do You Think is the Primary Task for Building Social Justice?" The result(Table 3) shows that 35.9\% of the respondents thought corruption should be cleared. $31.8 \%$ of the respondents thought that the social insurance system should be improved. $20.7 \%$ of them thought the industry's monopoly needed to be broken. $8.0 \%$ of the respondents chose to break the household registration system so that the public could enjoy equal social benefits in the geographical area. There are significant differences in the different survey "regions"(Figure 3). $40.7 \%$ of the respondents of Sohu thought it necessary to perfect the social insurance system. 31.8\% 
of the respondents of Tom thought we need to make social justice a priority. $41.7 \%$ of the respondents of Sina thought the corruption had seriously impeded the realization of social equity and justice.

Table 3 the statistic analysis of the responses toward question $3(\%)$

\begin{tabular}{cccccc}
\hline media & $\begin{array}{c}\text { clear } \\
\text { corruption }\end{array}$ & $\begin{array}{c}\text { Improve social } \\
\text { insurance system }\end{array}$ & $\begin{array}{c}\text { Break } \\
\text { monopol }\end{array}$ & $\begin{array}{c}\text { Cancel household } \\
\text { registration system }\end{array}$ & other \\
\hline Xilu & 34.7 & 36.5 & 16.7 & 7.5 & 4.6 \\
Sina & 41.7 & 32.7 & 12.5 & 10.6 & 2.5 \\
Tianya & 36.7 & 27.8 & 22.2 & 9.4 & 3.9 \\
Sohu & 31.6 & 40.7 & 19.7 & 5.9 & 2.1 \\
Tom & 33.6 & 22.8 & 31.8 & 7.5 & 4.3 \\
MOP & 37.1 & 30.2 & 21.1 & 7.1 & 3.5 \\
average & 35.9 & 31.8 & 20.7 & 8.0 & \\
\hline
\end{tabular}

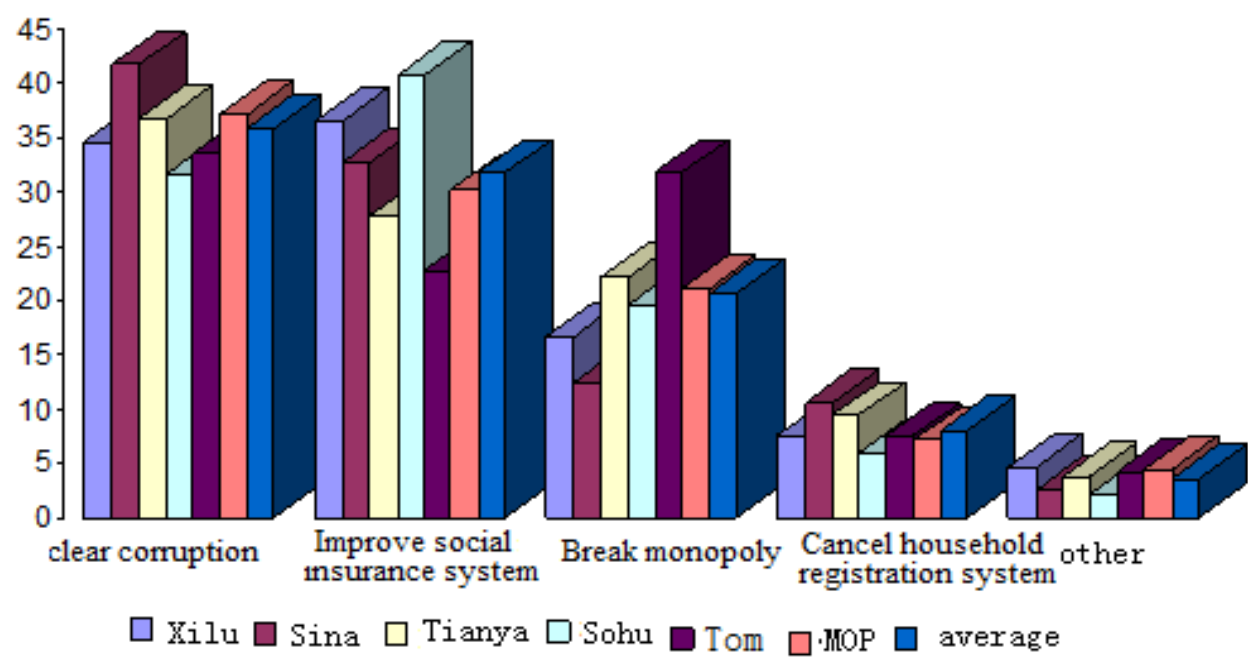

Figure 3 the cylindrical plot of the statistic analysis of the responses toward question 3

The Statistic Analysis of the Question "What Do You Think of the Development Trend of Our Society Justice?" Here is the result (Table 4): $34.7 \%$ of the respondents thought the society would be increasingly fair in the future. $33.5 \%$ of the respondents thought the society would be increasingly unfair in the future. The difference between the two is small, indicating that on this issue, the public is full of expectations and full of pessimism. It is found in the further research (Figure 4) that the respondents of Xilu and Sina held positive expectation toward the justice level of the society in the future. The proportion of choosing "increasingly fair" is $41.7 \%$ and $40.2 \%$ respectively. The respondents of Tianya and Tom held the opposite opinion. The proportion of choosing "increasingly unfair" is $43.7 \%$ and $43.9 \%$ respectively, more than the positive attitude of Xilu and Sina.

Table 4 the statistic analysis of the responses toward question 4 (\%)

\begin{tabular}{ccccc}
\hline media & increasingly fair & increasingly unfair & a little change & unclear \\
\hline Xilu & 41.7 & 21.5 & 25.4 & 11.4 \\
Sina & 40.2 & 21.9 & 19.5 & 18.4 \\
Tianya & 30.9 & 43.7 & 20.6 & 4.8 \\
Sohu & 37.5 & 33.2 & 18.4 & 10.9 \\
Tom & 32.8 & 43.9 & 15.4 & 7.9 \\
MOP & 23.7 & 36.8 & 27.6 & 11.9 \\
average & 34.7 & 33.5 & 21.2 & 10.9 \\
\hline
\end{tabular}




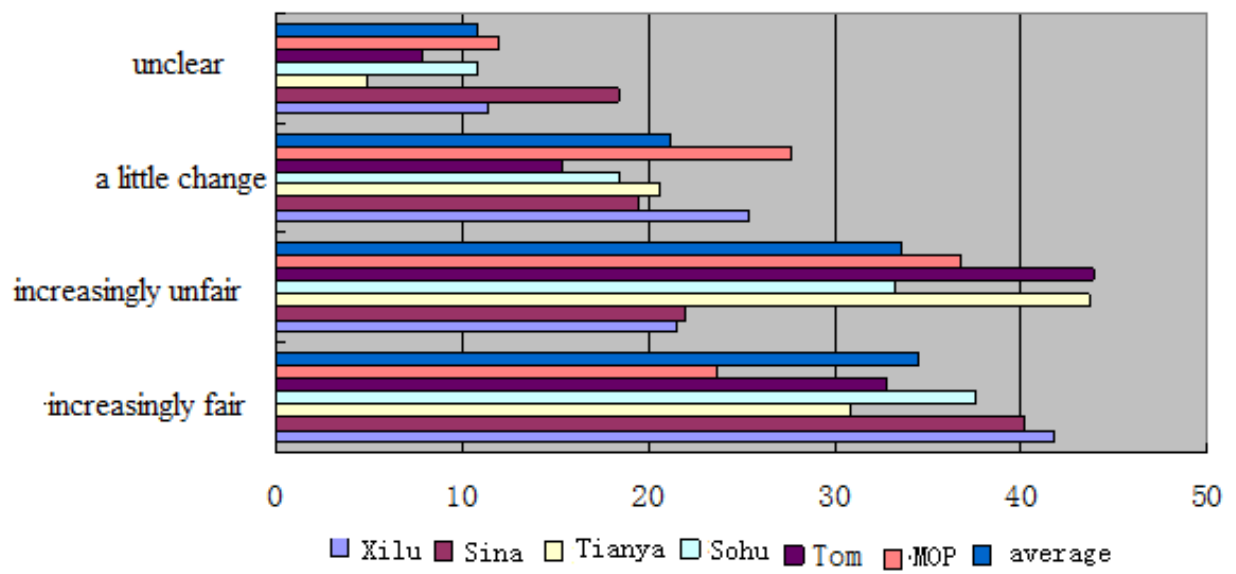

Figure 4 the cylindrical plot of the statistic analysis of the responses toward question 4

\section{Establish and Perfect the Institutional Guarantee Mechanism of Social Justice for Vulnerable Groups, and Fundamentally Ensure the Realization of Social Justice}

On the issue of social justice, groups with the strongest appeal must be vulnerable groups. In recent years, there has been a further expansion of this group, which is extremely bad to the development of the society in a better, faster direction.[8] Thus, this paper proposes to make different efforts from the following aspects.

Protect the Economic Interests of Vulnerable Groups from Damaging. For the vulnerable groups, the social Justice they face is mainly based on the justice of economic interests. Such interests should be protected rather than being damaged, missing, or being discounted. Therefore, it is necessary to establish and improve the institutional guarantee mechanism of social justice based on the vulnerable groups, so as to realize the balance of economic interests between social groups.[9] In order to achieve this, in addition to shorten the distance between the poor and the rich from the hierarchy of affluence by various methods, We should also actively increase the incomes of the poor, so that the wages of the vulnerable groups can be ensured and timely fulfilled. For urban residents, the subsistence allowance system should be established and improved to improve the amount and scope of the subsistence allowance, and ensure the economic interests of vulnerable groups in a fair category from the aspects of the system and even the law.

Enhance the Political Participation Rights of Vulnerable Groups. At present, although the political interests of vulnerable groups have been improved, but it is still in a partially damaged condition. It needs to carry out a comprehensive deeper level of improvement, and enhance the political participation rights of vulnerable groups. The problem is that preponderant groups tend to monopolize the interests in the process of formulating and implementing public policies, so that the demands of the vulnerable groups are difficult to be released and concerned. At the same time, the vulnerable groups in our country lack the necessary organizational forms of appeal. Their interests are often expressed in extreme or informal ways. This is not only a barrier to social development and stability, but also difficult to achieve the expectation. Therefore, it is proposed to establish and perfect the institutional guarantee mechanism for the justice system in political interests of vulnerable groups to ensure that the basic political rights of vulnerable groups can be achieved.

Promote the Improvement of Cultural Interests of Vulnerable Groups. In any society, social injustice will affect the social harmony of different classes and damage the destruction of social order. Therefore, in order to build a socialist harmonious society, we need to vigorously promote social justice construction. We should promote the construction of a harmonious society comprehensively and steadily by solving the problems affecting social justice and seek more interests for the public. In the present situation, the justice of cultural interests of vulnerable groups are in the condition of being damaged and missing. This has seriously affected the whole cultural literacy of this group, and directly or indirectly has cast a shadow over the construction of socialism with Chinese characteristics.[10] Therefore, it is necessary to promote the improvement of the cultural interests of 
the vulnerable groups. It is necessary to establish and perfect the institutional guarantee mechanism for the justice system in cultural interests of vulnerable groups. It is necessary to ensure that vulnerable groups enjoy fair access to public cultural resources. It is necessary to inspire the cultural vitality of vulnerable groups through social concern. At the same time, it is also necessary to guide vulnerable groups to do cultural creation. Only in this way can we achieve a real justice of cultural interests.

\section{Conclusion}

After 30 years of reform and opening up, the traditional market-oriented and efficiency-oriented social behavior has made an unprecedented growth and progress of China's material production and wealth. In this process, with the rapid development of the material field, there is a clear "paradox" between justice and efficiency -- The efficiency is extremely high, but justice declines. The voices of vulnerable groups are increasingly high for social justice. This makes us have to face this problem with a serious attitude, make a thorough analysis, find out the problems and solutions. Only in this way can we maximize the embodiment of the harmonious socialist society and realize the sustainable development of the economic society.

\section{Acknowledgements}

Fund Project:This paper is the Phased Achievement of the Philosophy and Social Science Project of Hennan "The Study on the Leading Value and Reality Reflection of the View of Social Justice in the New Normal" (2016BZZ008) .

\section{References}

[1] Hunag Ding. The Essence of Western Public Administration Theory [M], Beijing:China Renmin University Press,2005.

[2] George Frederickson. New Public Administration (English Version) [M].America:University of Alabama Press,1980.

[3] Gongcheng Zheng. An Analysis of Social Equity in China - Value Judgment, Equity Imbalance and System Guarantee [J]. Journal of Renmin University of China,2009 (2) :2-11.

[4] Wenliang Guo, Juyong Zhang. An Analysis of Social Equity in China's Vulnerable Groups [J]. A Study of Socialism with Chinese Characteristics,2006 (2) :81-84.

[5] KARL MARX and FREDERICK ENGELS: Volume 1 [M]. Beijing: People's Publishing House,1995.

[6] Xiaoliang Wang. Social Justice and Moral Concern of Vulnerable Groups [J]. Journal of Suihua University,2008 (8) :34-36.

[7] KARL MARX and FREDERICK ENGELS: Volume 1 (Version 2) [M]. Beijing: People's Publishing House,1995.

[8] Maohua Tang. The Path of Solving Income Distribution Problems [N]. China's Economic Development, 2006-10-03.

[9] Plerre Leroux. On Equality [M]. Beijing: Commercial Press,1988.

[10] John Rawls. A Theory of Justice [M]. Beijing:China Social Sciences Publishing House, 1988. 